\title{
The nurse work environment, job satisfaction and turnover rates in rural and urban nursing units
}

\author{
MARIANNE BAERNHOLDT, PhD , MPH, RN ${ }^{1}$ and BARBARA A. MARK, PhD , RN , FAAN ${ }^{2}$ \\ ${ }^{1}$ Assistant Professor, School of Nursing, University of Virginia, Charlottesville, VA \\ ${ }^{2}$ Sarah Frances Russell Distinguished Professor, University of North Carolina, Chapel Hill, NC, \\ USA
}

\section{Abstract}

\begin{abstract}
Aim-The aim of the present study was to determine whether there are differences in hospital characteristics, nursing unit characteristics, the nurse work environment, job satisfaction and turnover rates in rural and urban nursing units.
\end{abstract}

\begin{abstract}
Background-Research in urban hospitals has found an association between the nurse work environment and job satisfaction and turnover rates, but this association has not been examined in rural hospitals.
\end{abstract} Method-Rural and urban nursing units were compared in a national random sample of 97
United States hospitals (194 nursing units) with between 99 and 450 beds.

Results-Significant differences were found between hospital and nursing unit characteristics and the nurse work environment in rural and urban nursing units. Both nursing unit characteristics and the work environment were found to have a significant influence on nurse job satisfaction and turnover rates.

Conclusion-Job satisfaction and turnover rates in rural and urban nursing units are associated with both nursing unit characteristics and the work environment.

Implications for nursing management-Both rural and urban hospitals can improve nurse job satisfaction and turnover rates by changing unit characteristics, such as creating better support services and a work environment that supports autonomous nursing practice. Rural hospitals can also improve the work environment by providing nurses with more educational opportunities.

\section{Keywords}

job satisfaction; nurse work environment; rural/urban; turnover rates

\section{Introduction}

A growing body of research has linked poor nurse work environment to poor nurse outcomes (IOM 2004) such as poor job satisfaction and conditions conducive to costly nurse turnover (Jones 2008). Not only is nurse turnover expensive, but with a growing nursing shortage, hospitals face challenges in trying to recruit new nurses (Buerhaus 2005). Therefore, hospitals are increasingly examining how they can change their work 
environment to improve outcomes (Haynes 2008). Although there is emerging evidence of an association between nurse work environments and nurse outcomes (McGillis Hall 2003), this evidence is based on studies that primarily focused on large urban hospitals, making it uncertain whether work environments and nurse outcomes are also associated in rural hospitals.

It is also important to examine possible connections between poor work environments and poor nurse outcomes in rural hospitals, because these hospitals may find recruitment and retention particularly difficult. While rural hospitals in the United States (US) have lower vacancy rates overall than urban hospitals, more rural than urban hospitals have vacancy rates above 21\% (LaSala 2000). Among the reasons for the high vacancy rates is a recent increase in the number of rural nurses working outside their communities, perhaps because of the 22\% salary differential between rural and urban hospitals (Skillman et al. 2007). However, whether the high vacancy rates and the increase in rural nurses choosing to work in urban hospitals are also explained by differences in nurse work environments in rural and urban hospitals has not been examined.

While few studies have examined the nurse work environment and nurse outcomes in rural hospitals, vacancy rates have been linked to nurses' collaboration with physicians, and job satisfaction and intent to stay has been associated with management support and decentralization (Teasley et al. 2007, Stratton et al. 1998). In the few studies that included rural and urban comparisons, nurses working in rural hospitals used more and rated as more important support from management and they reported fewer support services than those in urban hospitals (MacPhee \& Scott 2002, LeSergent \& Haney 2005, Leipert \& Reutter 1998). Clearly, however, more research is needed on the nurse work environment's influence on nurse outcomes in rural hospitals.

Rural hospitals are the major force that organizes and delivers health care for the communities and at times they are the only available source of health care in a community (IOM 2005). Most of the US 2100 rural hospitals have fewer than 100 beds and limited technology (IOM 2005, AHA 2006). They also tend to have fewer nurses per patient and nurses with less education (Bushy 2000). The differences between rural and urban hospitals in number of beds, availability of technology, nurse/patient ratios and level of nurse education suggest that the nurse work environment might also differ. This study therefore examined whether the nurse work environment, job satisfaction and turnover rates differed in rural and urban hospitals.

\section{Conceptual model}

A conceptual model based on structural contingency theory (SCT) was developed to guide the study. According to SCT, context, structure and effectiveness are related such that an organization's effectiveness depends on a match between its context and structure (Donaldson 2001). If the internal structure does not take into account the context or the environment of the organization and the tasks it performs, effectiveness suffers. The present study adapted Mark et al.'s (1996) theoretical model for nursing systems to develop a conceptual model in which context was conceptualized as hospital and nursing unit characteristics, structure was conceptualized as the nurse work environment and effectiveness was conceptualized as nurse job satisfaction and turnover.

Context-Context was defined as the characteristics of the hospital environment and the complexity of work at hospital and nursing unit levels. Variables representing hospital characteristics were: member of integrated network or not, technological complexity and magnet status. Hospital size and whether a member of integrated network were included because larger organizations, either single institutions or a system, typically have more 
resources and support, which may affect the work environment and nurse outcomes (Mark et al. 2003, Daft 2007). Technological complexity was included because it has been associated with nurse work environments (Mark et al. 2003). Finally, a variable that identified whether a hospital had magnet accreditation or was pursuing accreditation was included because research has found higher job satisfaction in magnet hospitals (Brady-Schwartz 2005).

Nursing unit characteristics included size, work complexity, availability of support services and safety climate. Previously, these variables have been linked with the nurse work environment or nurse outcomes. For example, smaller unit size, more support services and higher safety climate have been linked with higher professional practice (Mark et al. 2007, 2003).

Structure-Structure was conceptualized as the nurse work environment, and operationalized as staffing adequacy and professional practice. Staffing adequacy included staffing measured as the proportion of registered nurses (RNs), vacancy rates, education, experience, expertise and commitment to care. Poor staffing has been associated with low job satisfaction and higher intent to leave, a predictor of turnover (McGillis Hall 2003, Vahey et al. 2004). Less education has been associated with poor work environments (Aiken et al. 2008); and higher vacancy rates have been related to poorer nurse work environment (Stratton et al. 1998). Possible linkages between nurse outcomes and experience, expertise and commitment to care have not been examined, but they were included because the Institute of Medicine (IOM 2004) suggests that these are important factors in the nurse work environment.

Professional practice was captured by work mechanisms and processes such as decentralization, autonomy and relational coordination with other health care professionals. Studies have found that higher levels of these variables were associated with higher job satisfaction (Larrabee et al. 2003, Vahey et al. 2004, Aiken et al. 2008).

\section{Method}

This is a secondary data analysis that examined differences between rural and urban hospitals in a subsample from the Outcomes Research in Nursing Administration (ORNA-II) project. ORNA-II was a large multi-site study testing the relationships between hospital context and structure, and organizational, nurse and patient outcomes. ORNA-II data collection began in 2003 and ended in 2004 (Mark et al. 2007). Although the original study utilized a longitudinal design, the study reported here examined cross-sectional relationships.

\section{Sample}

The ORNA-II sample was a national random sample of 286 general medical/surgical nursing units in 146 US hospitals. Hospitals had 99 beds or more, were non-federal, nonpsychiatric, not-for-profit acute care hospitals accredited by the Joint Commission. The subsample for this study included 194 nursing units from all 22 rural hospitals (99-450 beds) matched with 75 urban hospitals with the same number of beds. According to the American Hospital Association (AHA), a hospital was designated rural if it was located in a non-metropolitan statistical area, i.e. a geographic area with $<50000$ population.

\section{Data collection}

Data were collected from study coordinators, who were individuals appointed by the hospital to be responsible for the conduct of the study in their home institution and from surveys of RNs; and the annual survey of AHA. Data on hospital characteristics were 
obtained from AHA and from each hospital's study coordinator. Data on nursing unit characteristics were collected from study coordinators and nurse surveys. Nurses who participated were RNs who worked more than 20 hours/week in direct patient care and had worked on the participating units for more than 3 months. The nurses filled out surveys at three different time points and received incentives to participate and stay in the study, including individual and unit prizes.

\section{Measures}

The study included measures of hospital characteristics, nursing unit characteristics, the nurse work environment and nurse outcomes. Staff nurse data were aggregated to the nursing unit level using the mean for the unit as that unit's score. In order to assess agreement on the rating among the nurses within a unit, within-group inter-rater agreement was assessed using $r_{\mathrm{wg}}$, as suggested by Lindell et al. (1999), who recommend an $r_{\mathrm{wg}}$ of at least 0.60 . Internal consistency reliability for scales was evaluated using Cronbach's alpha. For all scales, alpha and $r_{\mathrm{wg}}$ were above the recommended minimum values (Tables 1 and 2).

Hospital characteristics-Hospital characteristics were hospital size, technological complexity, member of integrated network and magnet status. Hospital size was the number of licenced beds. In order to make meaningful comparisons of hospital size, the 22 rural hospitals were divided into three size categories: 99-199, 200-299 and 300-450 beds. Technological complexity was measured as a weighted number of the availability of 16 high technology services using the Saidin Index (Spetz \& Maiuro 2004). Member of an integrated network was a categorical variable. Magnet status was defined as whether the hospital had achieved or was in the process of applying for magnet accreditation.

Nursing unit characteristics-Nursing unit characteristics were size, work complexity, availability of support services and safety climate. Unit size was the number of beds on the unit. Work complexity was measured using a seven-item scale that asked nurses whether physicians' orders were changed frequently and whether the unit had a high number of transfers and admissions (Salyer 1996). Availability of support services was measured by a check list of 21 possible support services on which staff nurses indicated whether a specific service was available, not available, or inconsistently available (Mark et al. 2003). Safety climate was measured using a 25-item scale derived from Zohar's (1980) safety climate measure, revised by Mueller et al. (1999), and from the Error Orientation Scale (Rybowiak et al. 1999). The safety climate scale measures incentives for nurses to follow safety guidelines and practices, such as job duties that allow for safe performance, management's attitude toward safety, nurses' willingness to reveal errors and degree of open communication about errors.

The nurse work environment-The nurse work environment was operationalized as staffing adequacy and professional practice. Staffing adequacy was proportion of RNs, vacancy rate, experience, education, expertise and commitment to care. The proportion of RNs was the ratio of RNs to total number of nursing staff on the unit. Vacancy rate was the ratio of a unit's unfilled nursing positions to the total budgeted number of nursing positions. Education was the per cent of RNs with baccalaureate or higher degrees. Experience was the number of years working as an RN in direct patient care. Expertise was measured using an eight-item scale on which nurses rated the expertise of their nursing workgroup in terms of early recognition of patient problems, for example, ability to recognize subtle changes in patients and initiate appropriate actions (Minick \& Harvey 2003). Commitment to care was measured using an eight-item scale where nurses evaluated the extent to which nurses on their unit felt responsible for care, for example, whether they would continue to seek 
clarification/question the physician when an order did not quite make sense and whether they would approach and counsel a staff member who provided sub-standard care (Minick \& Harvey 2003).

Professional practice was decentralization, autonomy and relational coordination. Decentralization was measured using a six-item scale asking nurses to rate the extent of nurses' participation in decision-making about unit staffing and budgeting as well as planning and evaluating nursing care (Mark \& Hagenmueller 1994). Autonomy was measured using a 21-item scale that assessed the extent to which nurses felt they had freedom to make decisions, carry out and evaluate nursing care (Gerber 1990). Relational coordination was measured using an eight-item scale that asked RNs to rate the quality of collaboration between nurses and other health care professionals, including degree of coordination, shared knowledge, shared goals and mutual respect (Gittell et al. 2000).

Nurse outcomes-The two nurse outcomes were nurse job satisfaction and nurse turnover. Nurse job satisfaction was measured using a 27-item organizational job satisfaction scale (Hinshaw \& Atwood 1984). Turnover rates were calculated as the total number of RNs who ended their employment on the unit (resigned, retired, transferred to another unit, released or terminated by the hospital) during a 6-month period, divided by the average number of RNs on the unit for the same period.

\section{Data analysis}

Hospital characteristics were compared at the hospital level whereas data from the nurse surveys were aggregated to the nursing unit level and compared. spss version 12.0 (SPSS Inc., Chicago, IL, USA) and sAs version 9.0 (SAS Institute Inc., Cary, NC, USA) were used to compute results. The chi-squared-test was used for categorical variables. The student's $t$-test and Mann-Whitney non-parametric tests were used for continuous variables depending on whether or not a variable was normally distributed.

The relationships among characteristics of the hospital, nursing unit and the work environment and the nurse outcomes were examined using regression analysis and general estimating equations with hospital as the clustering variable (Stokes et al. 2000). Analyses were performed using stepwise deletion. For all results, likelihood ratio tests checking the chi-squared-test for differences between the full and reduced model verified that the final reduced model was better than the starting full model.

\section{Results}

Data on hospital and nursing unit characteristics obtained from the AHA annual survey and study coordinators were available for all hospitals and nursing units in the primary study and therefore also for the subsample for this study. In the primary study, the mean nurse response rate over all three time periods was $62 \%$. No information on non-respondents was available as nurse characteristics were obtained from the surveys.

\section{Hospital characteristics}

There were few significant differences between hospital characteristics in rural and urban hospitals. There were fewer rural hospitals than urban hospitals with 200-299 beds or 300450 beds $(P<0.0002)$. Rural hospitals were significantly lower in technological complexity $(P<0.04)$, indicating that they offered less complex technological procedures and equipment than urban hospitals. There were no statistically significant differences between rural and urban hospitals with regard to magnet status or whether a hospital was a member of an integrated network. 


\section{Nursing unit characteristics}

At the nursing unit level, four characteristics were compared based on rural and urban location and hospital size (Table 1). Nursing units in rural hospitals were significantly smaller than in urban hospitals ( 29.4 beds $v s .33 .8$ beds, $P<0.02$ ). Units in rural hospitals with 200-299 beds had 27.4 beds compared with 36.2 beds in urban hospitals $(P<0.003)$. Work complexity, availability of support services and safety climate were similar in the two groups and across hospital size.

\section{Nurse work environment}

For the nurse work environment, three variables differed significantly between rural and urban hospitals (Table 2). Compared with units in urban hospitals, the proportion of RNs was significantly lower in all rural hospitals $(50.1 \%$ vs. 59.6\%, $P<0.000)$, and in the units in rural hospitals with bed size categories of 200-299 $(P<0.01)$ and 300-450 $(P<0.000)$. Rural hospital units had a significantly lower proportion of RNs with baccalaureate or higher degree (27.2\% vs. 35.3\%, $P<0.006)$. This was true for all bed size categories, but only in hospitals with 200-299 beds was the difference significant (24.4\% vs. 35.1\%, $P<0.04)$. Vacancy rates were significantly lower in nursing units in rural hospitals $(8.5 \% \mathrm{Vs} .12 .7 \%, P$ $<0.004)$, and the difference was most pronounced for hospitals with 200-299 beds, where the vacancy rate was $6.3 \%$ compared with $14.8 \%$ in urban hospitals $(P<0.002)$. RNs' experience, expertise and commitment to care were almost identical in the two groups, as were the professional practice variables, decentralization, autonomy and relational coordination.

\section{Nursing outcomes}

Regression analyses revealed that rural/urban location was not significantly associated with nurse job satisfaction or turnover rates, but several characteristics of the nursing unit and factors in the nurse work environment were significantly associated with these outcomes. For the entire sample, availability of support services, commitment to care and autonomy had a significant positive influence on nurse job satisfaction. For the entire sample, a positive significant relationship was found between turnover rate and work complexity and unit vacancy rates.

\section{Discussion}

This study found a number of statistically significant differences between rural and urban hospitals. Several hospital characteristics, nursing unit characteristics and variables describing the nurse work environment, differed based on rural/urban location. As noted in previous studies, rural hospitals had fewer beds and offered fewer technologically complex procedures and equipment than urban hospitals (IOM 2005). However, nurse job satisfaction and turnover rates were not associated with rural/urban location or any other hospital characteristic.

Among nursing unit characteristics, only unit size differed between rural and urban nursing units: rural hospital units had fewer beds. Yet, size had no impact on job satisfaction or turnover rate. There were no differences between rural and urban nursing units in availability of support services and work complexity, the two unit characteristics that were linked to nurse job satisfaction and turnover rates. The association of less availability of support services with lower job satisfaction show that in order to feel they deliver quality care and are satisfied with their jobs, nurses need enough support staff, including unit secretarial support, house keeping, intravenous teams, social work services and dieticians, as well as supplies such as stocked linen and supply carts and delivery of medication and intravenous fluids. Previous studies have found that the availability of support service affect 
the work environment and nurse outcomes (Mark et al. 2003, Teasley et al. 2007). For example, an intervention that included increased administrative support improved nurses' perceptions of the work environment, job satisfaction and intent to stay (Teasley et al. 2007), and greater availability of support services has been found to predict enhanced professional nursing practice (Mark et al. 2003).

Our finding that increased work complexity was associated with higher turnover rate suggests that units with increased complexity create conditions in which nurses might leave because of less control over the patients assigned to them. The control is decreased with frequent changes in patient orders, for example, as a result of increased patient acuity and frequent transfers, admissions and discharges resulting in one nurse caring for a higher number of patients during a shift. Both increased patient acuity and a higher number of patients a nurse is personally responsible for during a shift have been associated with lower job satisfaction (Sherwood et al. 2005, McGillis Hall \& Doran 2007). If the increase in work complexity is not compensated by an increase in staff and/or support services, it is likely nurses may be dissatisfied enough to leave.

The relationship between higher vacancy rates and higher turnover rates makes intuitive sense. Nurses in units with higher vacancy rates may have a higher work load and therefore may more readily leave. As have been reported previously, in this study we found lower vacancy rates in rural hospitals than urban hospitals (LaSala 2000). The lower vacancy rates in rural hospitals could indicate on one hand that rural nurses have limited alternative sources of employment and therefore stay in their jobs (Phillips \& McLeroy 2004), or on the other hand that rural nurses stay because of the often higher quality of life and community connectedness that rural communities offer (Baernholdt \& Jennings 2007). In the near future, both rural and urban hospitals will face rising vacancy rates because of the expected retirement of much of the ageing nurse workforce in both settings (Skillman et al. 2006). Therefore, more studies are needed to determine if vacancy rates do have implications for nurse outcomes.

Our study found higher commitment to care and more autonomy were associated with increased job satisfaction. Autonomy, or the ability to exercise independent nursing judgment for patients, has been widely cited as one of the most important factors in nurse job satisfaction (Sengin 2003). In contrast, commitment to care, or the extent to which nurses perceive that the nurses on their unit feel responsible for care, has not been included in previous studies. However, feeling responsible and able to influence ones' work has been linked to job satisfaction in previous studies (Laschinger et al. 2001).

Some nurse work environment factors differed in rural and urban hospitals. As found in other studies (Bushy 2004), rural nursing units had a lower proportion of RNs and fewer nurses who held a baccalaureate or higher degree. While these factors were not associated with nurse outcomes, rural nurses have said that maintaining clinical and professional competency is a major challenge (Newhouse 2005). There are limited educational opportunities in rural areas, and therefore, it is difficult for nurses to advance their education. Solutions could include development of nursing programmes closer to rural areas, such as outreach programmes to local community colleges from established institutions and opportunities to enrol in degree programmes through on-line or telecommunication (IOM 2005). Another option is to use nursing loan repayment programmes in exchange for work in rural areas (IOM 2005, Thaker et al. 2008). However, rural hospitals also need to reward nurses for obtaining higher degrees. Rural RNs with baccalaureate degrees currently earn less than their urban colleagues (Skillman et al. 2007). 
This study had several limitations. First, 'rural' was defined as a non-metropolitan statistical area, but this definition of rural is broad. A more detailed definition, using degree of rurality as suggested by Hart et al. (2004), might result in a different division of hospitals into rural and urban categories and therefore possibly different results. Second, while a $62 \%$ response rate is considered high in survey research (Dillman 2007), it still does suggest that a sizable portion of the study sample did not respond. Finally, this study used a small random sample of hospitals with between 99 and 450 beds in the US. About two-thirds of US rural hospitals have $<100$ beds (Colgan 2002), so research using samples of hospital with $<100$ beds and in other countries is warranted. Nonetheless, our findings suggest that factors associated with higher levels of nurse job satisfaction and lower turnover rates are the same in both rural and urban hospitals. Given that in the US the cost of nurse turnover, including recruitment and training of new hires, is estimated between $\$ 82000$ per RN (for an experienced RN) and $\$ 88000$ (for a new RN) (Jones 2008), institutions can save a significant amount of money with even modest decreases in nurse turnover rates.

\section{Conclusion}

Therefore, for both rural and urban hospitals, it is prudent to examine the work environment as part of an overall plan to improve nurse outcomes. Creating better support services, work flow with less complexity, a nurse work environment that supports autonomous nursing practice and nurses who are committed to their care should be part of both rural and urban hospitals' plans for change in order to recruit and retain nurses.

\section{Acknowledgments}

This study was supported by the National Institute of Nursing Research (T32 NR008856 and R01NR03149).

\section{References}

AHA, American Hospital Association. Hospital Statistics 2006 edition. Health Forum, LLC; Chicago: 2006.

Aiken LH, Clarke SP, Sloane DM, Lake ET, Cheney T. Effects of hospital care environment on patient mortality and nurse outcomes. Journal of Nursing Administration. 2008; 38:223-229. [PubMed: 18469615]

Baernholdt, M.; Jennings, BM. Quality is What Rural Hospitals are all About. Presentation at the International Nursing Administration Conference; Indianapolis, IN. 2007.

Brady-Schwartz DC. Further evidence on the Magnet recognition program. Journal of Nursing Administration. 2005; 35:397-403. [PubMed: 16200007]

Buerhaus PI. Six-part series on the state of the RN workforce in the United states. Nursing Economics. 2005; 23:58-60. [PubMed: 15881490]

Bushy, A. Orientation to Nursing in the Rural Community. Sage Publications Inc; Thousand Oaks, CA: 2000.

Bushy A. Creating nursing research opportunities in rural healthcare facilities. Journal of Nursing Care Quality. 2004; 19:162-168. [PubMed: 15077834]

Colgan, CS. The Economic Effect of Rural Hospital Closures. Rural Health Research Center, University of Southern Maine; Portland, ME: 2002.

Daft, RL. Organization Theory and Design. 9th edn. Thomson; Southwestern, Mason, OH: 2007.

Dillman, DA. Mail and Internet Surveys. The Tailored Design Method. John Wiley \& Sons, Inc.; New York, NY: 2007.

Donaldson, L. The Contingency Theory of Organizations. Sage Publications Inc; Thousand Oaks, CA: 2001.

Gerber, R. Control Over Nursing Practice Scale. Paper presented at the National Conference on Instrumentation in Nursing; Tucson, AZ. University of Arizona; 1990. 
Gittell JH, Fairfield KM, Bierbaum B, et al. Impact of relational coordination on quality of care, postoperative pain and functioning, and length of stay: a nine-hospital study of surgical patients. Medical Care. 2000; 38:807-819. [PubMed: 10929993]

Hart LG, Larson EH, Lishner DM. Rural definitions for health policy and research. American Journal of Public Health. 2004; 95:1149-1155. [PubMed: 15983270]

Haynes, VD. [accessed on 13 September 2008] What nurses want. 2008. Washington Post. Available at: http://www.washingtonpost.com/wp-dyn/content/article/2008/09/12/AR2008091203367.html

Hinshaw, AS.; Atwood, JR., editors. Nursing Staff Turnover, Stress, and Satisfaction: Models, Measures, and Management. Vol. Vol. 1. Springer; New York, NY: 1984.

IOM, Institute of Medicine. Keeping Patients Safe. Transforming the Work Environment of Nurses. The National Academies Press; Washington, DC: 2004.

IOM, Institute of Medicine. Quality Through Collaboration. The Future of Rural Health. The National Academies Press; Washington, DC: 2005.

Jones CB. Revisiting nurse turnover costs. Journal of Nursing Administration. 2008; 38:11-18. [PubMed: 18157000]

Larrabee JH, Janney MA, Ostrow C. Predicting registered nurse job satisfaction and intent to leave. Journal of Nursing Administration. 2003; 33:271-283. [PubMed: 12792282]

LaSala KB. Nursing workforce issues in rural and urban settings - looking at the difference in recruitment, retention, and distribution. Online Journal of Rural Nursing and Health Care. 2000; $1: 8-17$.

Laschinger HKS, Finigan J, Shamian J. Promoting nurses' health: effect of empowerment on job strain and work satisfaction. Nursing Economics. 2001; 19:42-52.

Leipert B, Reutter L. Women's health and community health nursing practice in geographically isolated settings: a Canadian perspective. Health Care for Women International. 1998; 19:575588. [PubMed: 9849202]

LeSergent CM, Haney CJ. Rural hospital nurses' stressors and coping strategies: a survey. International Journal of Nursing Studies. 2005; 42:315-324. [PubMed: 15708018]

Lindell MK, Brandt CJ, Whitney DJ. A revised index of interrater Agreement for multi-item ratings of a single target. Applied Psychological Measurement. 1999; 23:127-135.

MacPhee M, Scott J. The role of social support networks for rural hospital nurses. Journal of Nursing Administration. 2002; 32:264-272. [PubMed: 12021567]

Mark BA, Hagenmueller AC. Technological and environmental characteristics of intensive care units: implications for job re-design. Journal of Nursing Administration. 1994; 24(4S):65-71. [PubMed: 8151437]

Mark BA, Salyer J, Smith CS. A theoretical model for nursing systems. Nursing Administration Quarterly. 1996; 20:12-27. [PubMed: 8717945]

Mark BA, Salyer J, Wan TTH. Professional nursing practice impact on patient outcomes. Journal of Nursing Administration. 2003; 33:224-234. [PubMed: 12690254]

Mark BA, Hughes LC, Belyea M, et al. Does safety climate moderate the influence of staffing adequacy and work conditions on nurse injuries? Journal of Safety Research. 2007; 38:431-446. [PubMed: 17884430]

McGillis Hall, L. Nursing outcomes: nurses' job satisfaction. In: Doran, DM., editor. NursingSensitive outcomes. State of the Science. Jones and Bartlett Publishers; Sudbury, MA: 2003. p. 238-318.

McGillis Hall L, Doran D. Nurses' perceptions of hospital work environments. Journal of Nursing Management. 2007; 15:264-273. [PubMed: 17359426]

Minick P, Harvey S. The early recognition of patient problems among medical-surgical nurses. Medsurg Nursing. 2003; 12:291-297. [PubMed: 14608685]

Mueller, L.; DaSilva, N.; Townsend, J.; Tetrick, L. An Empirical Evaluation of Competing Safety Climate Measurement Models. Paper presented at the Annual Meeting of the Society for Industrial and Organizational Psychology; Atlanta, GA. 1999.

Newhouse R. Exploring nursing issues in rural hospitals. Journal of Nursing Administration. 2005; 35:350-358. [PubMed: 16077277] 
Phillips CD, McLeroy KR. Health in rural America: remembering the importance of place. American Journal of Public Health. 2004; 94:1661-1663. [PubMed: 15451725]

Rybowiak V, Garst H, Frese M, Batinic B. Error orientation questionnaire (EOQ): reliability, validity, and different language equivalence. Journal of Organizational Behavior. 1999; 20:527-547.

Salyer J. Development and psychometric evaluation of an instrument to measure staff nurses' perception of uncertainty in the hospital environment. Journal of Nursing Measurement. 1996; 4:33-48. [PubMed: 8936887]

Sengin KK. Work-related attributes of RN job satisfaction in acute care hospitals. Journal of Nursing Administration. 2003; 33:317-320. [PubMed: 12796627]

Sherwood L, Hunt J, Hagen S, Macleod M, Ball J. The relationship between UK hospital nurse staffing and emotional exhaustion and job dissatisfaction. Journal of Nursing Management. 2005; 13:51-60. [PubMed: 15613094]

Skillman SM, Palazzo L, Keepnews D, Hart G. Characteristics of registered nurses in rural versus urban areas: implications for strategies to alleviate nursing shortages in the United States. Journal of Rural Health. 2006; 22:151-157. [PubMed: 16606427]

Skillman, SM.; Palazzo, L.; Hart, GL.; Butterfield, P. Changes in the Rural Registered Nurse Workforce from 1980 to 2004. University of Washington, WWAMI Rural Health Research Center; Seattle, WA: 2007.

Spetz J, Maiuro LS. Measuring levels of technology in hospitals. The Quarterly Review of Economics and Finance. 2004; 44:430-437.

Stokes, ME.; Davis, CS.; Koch, GG. Categorical Data Analysis Using the SAS System. 2nd edn. SAS Publishing; Cary, NC: 2000.

Stratton T, Dunkin J, Szigeti E, Muus J. Recruitment barriers in rural community hospitals: a comparison of nursing and nonnursing factors. Applied Nursing Research. 1998; 11:264-271.

Teasley SI, Sexton KA, Carroll CA, Cox KS, Riley M, Ferriell K. Improving work environment perceptions for nurses employed in a rural setting. Journal of Rural Health. 2007; 23:179-182. [PubMed: 17397376]

Thaker S, Pathman D, Mark BA, Ricketts T. Service-linked scholarships, loan and loan-repayment programs for nurses in the southeast. Journal of Professional Nursing. 2008; 24:122-130. [PubMed: 18358448]

Vahey DC, Aiken LH, Sloane DM, Clarke SP, Vargas D. Nurse burnout and patient satisfaction. Medical Care. 2004; 42:II57-II64. [PubMed: 14734943]

Zohar D. Safety climate in industrial organizations: theoretical and applied implications. Journal of Applied Psychology. 1980; 65:96-102. [PubMed: 7364709] 


\section{Table 1}

Comparison of nursing unit characteristics in rural and urban hospital units $(n=194)$

\begin{tabular}{|c|c|c|c|c|c|c|c|}
\hline & Rural $(n=44)$ & Urban $(n=150)$ & Range & & Test & Alpha & $r_{\text {wg }}$ \\
\hline \multicolumn{8}{|l|}{ Unit size mean(SD) } \\
\hline 99-199 & $26(7.8)$ & $28.9(6.4)$ & $13-41$ & $\mathrm{~ns}$ & MW & & \\
\hline $200-299$ & $27.4(6.4)$ & $36.2(12.2)$ & $15-70$ & $P<0.003$ & MW & & \\
\hline $300-450$ & $34.4(9.3)$ & $33.6(10.7)$ & $13-60$ & ns & MW & & \\
\hline Total & $29.4(8.7)$ & $33.8(11.0)$ & $13-74$ & $P<0.02$ & MW & & \\
\hline Work complexity & $25.9(4.4)$ & $27.2(3.3)$ & $15.8-37.4$ & ns & $t$-test & 0.85 & 0.70 \\
\hline Support services & $32.5(2.3)$ & $32.3(2.6)$ & $23-39.2$ & $\mathrm{~ns}$ & $t$-test & 0.81 & 0.71 \\
\hline Safety climate & $10.2(0.8)$ & $10.2(0.8)$ & $8.3-12.7$ & ns & $t$-test & 0.95 & 0.83 \\
\hline
\end{tabular}

MW, Mann-Whitney non-parametric test; bold indicates statistically significant results.

Results according to number of beds not shown if not at least one category was statistically significant.

Alpha and $r_{\mathrm{Wg}}$ is reported for the whole sample $(n=194)$. 
Table 2

Comparison of the nurse work environment in rural and urban hospital units $(n=194)$

\begin{tabular}{|c|c|c|c|c|c|c|c|}
\hline Staffing Adequacy & Rural $(n=44)$ & $\operatorname{Urban}(n=150)$ & Range & & Test & Alpha & $r_{\mathrm{wg}}$ \\
\hline \multicolumn{8}{|l|}{ Proportion of RNs (\%) } \\
\hline $99-199$ & $51(16.5)$ & $56.4(11.3)$ & $23.3-75.2$ & ns & $t$-test & & \\
\hline $200-299$ & $50.6(15.6)$ & $61.1(12.8)$ & $25.5-87.7$ & $P<0.01$ & $t$-test & & \\
\hline $300-450$ & $48.9(6.7)$ & $59.4(14.2)$ & $27.9-100$ & $P<0.000$ & $t$-test & & \\
\hline Total & $50.1(13.1)$ & $59.6(13.5)$ & $23.3-100$ & $P<0.000$ & $t$-test & & \\
\hline \multicolumn{8}{|l|}{ Vacancy rate $(\%)$} \\
\hline 99-199 & $10.5(8.1)$ & $11.4(6.0)$ & $0.6-24$ & ns & MW & & \\
\hline 200-299 & $6.3(6.1)$ & $14.8(10.1)$ & $0-45.1$ & $P<0.002$ & MW & & \\
\hline $300-450$ & $8.7(10.3)$ & $11.7(10.5)$ & $0-51.2$ & ns & MW & & \\
\hline Total & $8.5(8.5)$ & $12.7(10.1)$ & $0-51.4$ & $P<0.004$ & MW & & \\
\hline Experience (years as RN) & $11.1(4)$ & $11.8(4)$ & $3.6-26.9$ & $\mathrm{~ns}$ & MW & & \\
\hline \multicolumn{8}{|c|}{ Education (\% of RNs with a BS or higher degree) } \\
\hline 99-199 & $18.3(12.6)$ & $30.5(20.9)$ & $0-63.6$ & ns & MW & & \\
\hline $200-299$ & $24.4(15.6)$ & $35.1(16.7)$ & $0-70$ & $P<0.04$ & MW & & \\
\hline $300-450$ & $37.5(26.6)$ & $36.3(18.6)$ & $0-100$ & $\mathrm{~ns}$ & MW & & \\
\hline Total & $27.2(20.1)$ & $35.3(18.3)$ & $0-100$ & $P<0.006$ & MW & & \\
\hline Expertise & $41.8(2.6)$ & $42.5(2.1)$ & $34.8-46.9$ & ns & MW & 0.92 & 0.89 \\
\hline Commitment to care & $36(2.3)$ & $36.6(1.9)$ & $29.2-40.9$ & ns & MW & 0.81 & 0.84 \\
\hline \multicolumn{8}{|l|}{ Professional practice } \\
\hline Decentralization & $15.1(2.1)$ & $15.5(2.0)$ & $9.4-21.2$ & $\mathrm{~ns}$ & $t$-test & 0.77 & 0.84 \\
\hline Autonomy & $88.4(6.4)$ & $89.5(5.8)$ & $68.5-103.5$ & ns & $t$-test & 0.92 & 0.88 \\
\hline Relational coordination & 225.5 (11.3) & $227.1(11.7)$ & $196-262.8$ & ns & MW & 0.96 & 0.86 \\
\hline
\end{tabular}

MW, Mann-Whitney non-parametric test; bold indicates statistically significant results.

Results according to number of beds not shown if not at least one category was statistically significant. Alpha and $r_{\mathrm{Wg}}$ is reported for the whole sample $(n=194)$. 